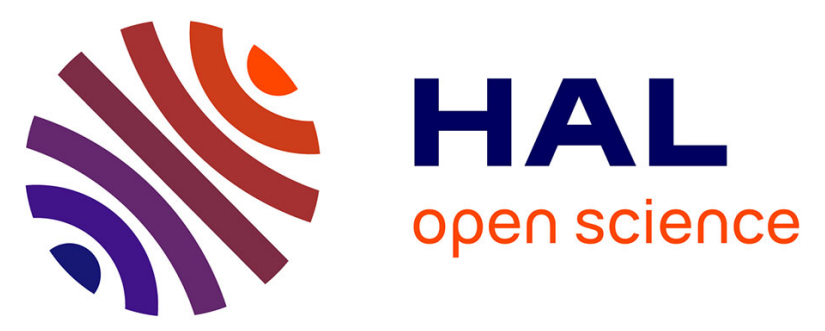

\title{
Hydrocarbons and heavy metals in the different sewer deposits in the 'Le Marais' catchment (Paris, France): stocks, distributions and origins
}

Vincent Rocher, Sam Azimi, Régis Moilleron, Ghassan Chebbo

\section{- To cite this version:}

Vincent Rocher, Sam Azimi, Régis Moilleron, Ghassan Chebbo. Hydrocarbons and heavy metals in the different sewer deposits in the 'Le Marais' catchment (Paris, France): stocks, distributions and origins. Science of the Total Environment, 2004, 323, pp.107 - 122. 10.1016/j.scitotenv.2003.10.010 . hal-01087695

\section{HAL Id: hal-01087695 \\ https://hal-enpc.archives-ouvertes.fr/hal-01087695}

Submitted on 26 Nov 2014

HAL is a multi-disciplinary open access archive for the deposit and dissemination of scientific research documents, whether they are published or not. The documents may come from teaching and research institutions in France or abroad, or from public or private research centers.
L'archive ouverte pluridisciplinaire HAL, est destinée au dépôt et à la diffusion de documents scientifiques de niveau recherche, publiés ou non, émanant des établissements d'enseignement et de recherche français ou étrangers, des laboratoires publics ou privés.

\section{(c)(1)}

Distributed under a Creative Commons Attribution| 4.0 International License 


\title{
Hydrocarbons and heavy metals in the different sewer deposits in the 'Le Marais' catchment (Paris, France): stocks, distributions and origins
}

\author{
Vincent Rocher ${ }^{\mathrm{a}, *}$, Sam Azimi ${ }^{\mathrm{a}}$, Régis Moilleron ${ }^{\mathrm{a}}$, Ghassan Chebbo ${ }^{\mathrm{b}, \mathrm{c}}$ \\ ${ }^{a}$ Cereve, Faculté de Sciences et de Technologie, Université Paris XII-Val de Marne, 61 Avenue du Général de Gaulle, Créteil, \\ Cedex 94010, France \\ ${ }^{\mathrm{b}}$ Cereve, Ecole Nationale des Ponts et Chaussées, Cité Descartes, 6-8 Avenue Blaise Pascal, Marne La Vallée, Cedex 277455 , \\ France \\ ${ }^{\mathrm{c}}$ Faculté de Génie, Université Libanaise, Route de l'aéroport, Beyrouth, Lebanon
}

Received 22 August 2003; received in revised form 12 September 2003; accepted 2 October 2003

\begin{abstract}
The knowledge of the pollution stored in combined sewers is of prime importance in terms of management of wet weather flow pollution since sewer deposits play a significant role as source of pollution in combined sewer overflows. This work, which focused on the hydrocarbon (aliphatic and aromatic hydrocarbons) and metallic ( $\mathrm{Fe}, \mathrm{Zn}, \mathrm{Pb}, \mathrm{Cu}$ and $\mathrm{Cd}$ ) pollution fixed to the different kinds of sewer deposits (gross bed sediment [GBS], organic layer [OL] and biofilm), was performed in order to provide a complete overview of the contaminant storage in the 'Le Marais' combined sewer (Central Paris, France). Firstly, our results have shown that, for all kinds of pollutants, a major part was stored in the GBS ( 87 to $98 \%$ ), a lesser part in the OL (2 to 13\%) and an insignificant part in the biofilm $(<$ $1 \%$ ). These results demonstrated that the potential contribution of biofilm to wet weather pollution was negligible compared to the OL one. Secondly, the investigation of hydrocarbon fingerprints in each deposit has provided relevant information about contamination origins: (1) aliphatic hydrocarbon distributions were indicative of petroleum input in the GBS and reflected a mixture of biogenic and petroleum inputs in the OL and biofilm, (2) aromatic hydrocarbon distributions suggested an important pyrolytic contamination in all the deposits. Finally, the study of pollutant fingerprints in the different deposits and in the suspended solids going through the collector has shown that: (1) the suspended solids were the major component of OL and biofilm while urban runoff seemed to be the main transport mechanism introducing pollutants in the GBS and (2) the residence times in sewer of OL and biofilm were quite short compared to those for GBS.
\end{abstract}

(c) 2003 Elsevier B.V. All rights reserved.

Keywords: PAHs; $n$-alkanes; Heavy metals; Combined sewer; Fingerprints

\footnotetext{
*Corresponding author. Tel.: + 33-1-45-17-16-21; fax: 33-1-45-17-16-27.

E-mail addresses: vrocher@univ-paris12.fr (V. Rocher), moilleron@univ-paris12.fr (R. Moilleron).
} 


\section{Introduction}

The importance of the combined sewer overflow (CSO) pollution and its acute impact on receiving waters have been largely demonstrated. Today, reduction of CSO discharges has become a major concern for many municipalities both in order to recover the quality of the receiving water bodies and in order to meet the new European regulations. The development of CSO management strategies requires an improved knowledge on the pollutant loads in sewer deposits since many authors have underlined their significant role as source of pollution in CSO discharges (Bachoc, 1992; Chebbo, 1992; Krejci et al., 1994; Gromaire, 1998).

Three different categories of sewer deposits have been defined by several authors (Crabtree, 1989; Ahyerre, 1999). Sewer bed deposit, accumulated during dry weather flow periods, can be subdivided into two kinds of deposits: the gross bed sediment (GBS) and the organic layer (OL). The GBS, which has a high mineral content, looks very dark (black and grey) and its particles appear well defined with millimetric diameters, whereas the OL, which has a high organic content, shows a brown colour (Ahyerre et al., 2000; Oms et al., 2003). The third type of deposit is the biofilm. It is composed of a bacteria layer (5- to $10-\mu \mathrm{m}$ thick), which totally covers an organic matrix (1- to 5-mm thick). This complex is attached to the trunk wall at the mean water level (Rocher et al., 2003a).

This work focused on hydrocarbon and heavy metal pollutants, which can have a harmful damaging effect on human and environmental health. Aliphatic hydrocarbons, polycyclic aromatic hydrocarbons (PAHs) and heavy metals (iron [Fe], zinc $[\mathrm{Zn}]$, lead $[\mathrm{Pb}]$, copper $[\mathrm{Cu}]$ and cadmium [Cd]) were measured in the different sewer deposits and in the waste water (suspended solids [SS] and dissolved phase [DP]) sampled in the combined sewer of the 4th district of Paris (down town). This research program was aimed at:

- investigating the hydrocarbon and heavy metal stocks in the different sewer deposits and assessing the potential contribution of each deposit to the wet weather pollution,
- characterising the hydrocarbon and metallic fingerprints in each sewer deposit,

- elucidating the hydrocarbon origins using aliphatic and aromatic distribution indexes, and

- studying the formation processes and the residence times of each deposit using the hydrocarbon and metallic signatures.

\section{Materials and methods}

\subsection{Sampling site}

This research was performed on a 42 ha experimental urban catchment, the 'Le Marais' catchment, located in the historical centre of Paris (Chebbo et al., 2001). It is a densely populated residential area (295 inhabitants per hectare) with small businesses and almost no industrial activities. The catchment area can be divided into three kinds of urban surfaces, leading to three types of runoff: roofs $(54.5 \%)$, streets $(23 \%)$ and surfaces such as courtyards, public squares and gardens $(22.5 \%)$ (Gromaire et al., 2001). 90\% of the catchment is impervious, which is typical of a dense town centre. The sewer network is combined and completely man-entry. It includes three ovoid trunks ('Vieille du Temple', 'St. Gilles' and 'Rivoli') and approximately 50 egg-shaped collectors (Fig. 1). 'Vieille du Temple' and 'St. Gilles' trunks flow into 'Rivoli'. Experiments were carried out in the 'St. Gilles' trunk, which is 798-m long, with a rectangular flow section of 0.7-m height and 0.6$\mathrm{m}$ width and an equivalent slope of $0.04 \%$. It was chosen because it contained a significant amount of all types of sewer deposits.

\subsection{Sampling procedures}

Bed deposits, i.e. the GBS and the OL, were sampled at the top of the 'St. Gilles' trunk (600 $m$ upstream 'Rivoli' trunk). The biofilm was sampled every 25 to $50 \mathrm{~m}$ from the St. Gilles-Rivoli junction up to $600 \mathrm{~m}$ upstream (Fig. 1). The GBS was sampled with an adapted shovel that isolated the sediment during sampling and trapped the fine particles of the sediment (Fig. 2). The system used to sample the OL was composed of a PVC box $(85 \times 30 \times 50 \mathrm{~cm})$ opened on two opposite sides 

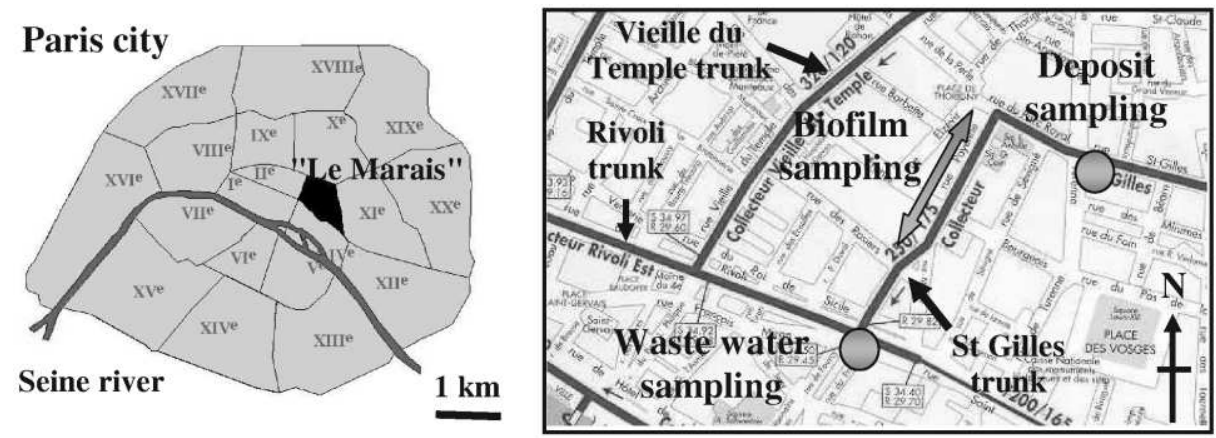

Fig. 1. Location of deposit and waste water sampling in the 'Le Marais' experimental urban catchment (Central Paris).

so that water can flow through it (Ahyerre et al., 2000). Two panels closed the box. The unit was inserted into the GBS in the direction of the flow. Samples were taken after each 5 to 10 dry weather day period. For sampling, the two panels were lowered and the water in the box was pumped out with a peristaltic pump. When all the waste water was pumped, the OL was scraped until reaching the GBS. The GBS and the OL were sampled simultaneously during 2 months (from January to February 2001) and five samples were collected. The biofilm, attached to the pipe wall, was scraped off using a little metallic scraper for hydrocarbon analysis and using a porcelain scraper for metal analysis; 14 and 17 samples were collected, in December 2000, for hydrocarbon and metal measurements, respectively (Rocher et al., 2003a).

Waste water was sampled using an automatic sampler (Buhler PBMOS) located in the 'St. Gilles' trunk. Samples were taken in the mid-depth of the flow with a sampling hose of $1-\mathrm{cm}$ diameter.
The sampler pumped $100 \mathrm{ml}$ per hour during 24 h. Then, all sub-samples were mixed in one sample. From February to March 2002, seven waste water samples were collected.

\subsection{Experimental procedures}

\subsubsection{Physico-chemical parameters}

The physico-chemical nature of the sewer deposits was investigated since all samples were analysed for volatile solid content (VSC), established following the NFU-44-160 AFNOR method (calcination at $480{ }^{\circ} \mathrm{C}$ ), and for water content (dried until constant weight at $40{ }^{\circ} \mathrm{C}$ ).

\subsubsection{Hydrocarbon analysis}

All samples were analysed for the aliphatic hydrocarbons ( $n$-C10 to $n$-C33) and the 16 PAHs selected from the US-EPA priority list and their alkylated derivatives. All solvents used for hydrocarbon analysis were purified by distillation. To a)

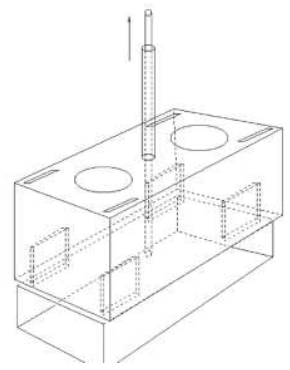

b)

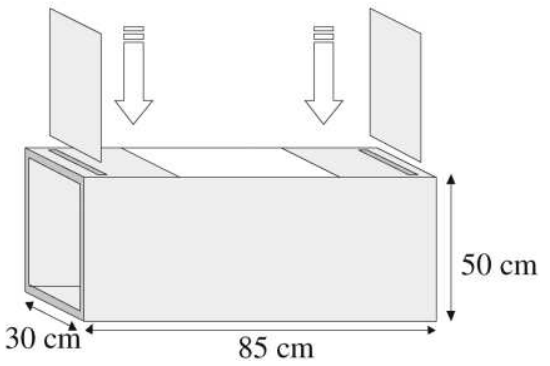

Fig. 2. Sampling system for (a) gross bed sediment and (b) organic layer (Ahyerre et al., 2000). 
avoid contamination, the glassware used for sampling and analysis was cleaned with 5\% Decon detergent (Prolabo), rinsed with deionised water (Milli-Ro, Millipore SA) and heated at $450{ }^{\circ} \mathrm{C}$ for $2 \mathrm{~h}$ to eliminate any trace of organic matter.

Extraction procedures depended on the type of samples. For deposit samples (GBS, OL and biofilm), approximately $1-2 \mathrm{~g} \mathrm{dw}$ (dry weight) were Soxwave (Prolabo) extracted for $10 \mathrm{~min}$ with a $\mathrm{CH}_{2} \mathrm{Cl}_{2}-\mathrm{MeOH}$ mixture $(35 \mathrm{ml} / 5 \mathrm{ml})$ after addition of perdeuterated internal standards (dodecane $\mathrm{D}_{26}$, tetracosane $\mathrm{D}_{50}$, triacontane $\mathrm{D}_{62}$, naphthalene $\mathrm{D}_{8}$, phenanthrene $\mathrm{D}_{10}$, pyrene $\mathrm{D}_{10}$ and benzo[a]pyrene $\left.\mathrm{D}_{12}\right)$. The extract was then concentrated to dryness under nitrogen flux (N5.0, Linde Gaz). Then $500 \mu$ l of hexane (Merck) were added. For liquid samples (waste water), an aliquot, typically 21 , was filtered by using a succession of pre-combusted and pre-extracted filters, from 2.7 $\mu \mathrm{m}$ (GF/F, Whatman) to $0.45 \mu \mathrm{m}$ (Millipore), in a glass filtration unit in order to separate dissolved and particulate phases. Particulate matter was dried to a constant weight at $40{ }^{\circ} \mathrm{C}$ and Soxwave extracted in the same way as deposit samples. After addition of perdeuterated internal standards, the dissolved phase was extracted by simple liquid-liquid extraction in a separation funnel using four successive $30 \mathrm{ml}$ additions of $\mathrm{CH}_{2} \mathrm{Cl}_{2}$ (Merck). Before the last extraction, sample $\mathrm{pH}$ was adjusted to 2 using concentrated $\mathrm{H}_{2} \mathrm{SO}_{4}$ (Merck). Each of the four portions was shaken with the filtrate sample for $10 \mathrm{~min}$. The extracts were then combined, dried using $\mathrm{CaCl}_{2}$ (Prolabo) and concentrated to approximately $5 \mathrm{ml}$ using a rotary evaporator at room temperature under vacuum. This fraction was further evaporated to dryness under nitrogen flux. Then $500 \mu l$ of hexane were added.

These aliquots were fractionated into two fractions on a chromatographic column of $2 \mathrm{~g}$ of activated silica gel (Aldrich, $5.5 \mathrm{~mm} \mathrm{ID} \times 30 \mathrm{~cm}$ in length), with $4 \mathrm{ml}$ hexane and $6 \mathrm{ml} \mathrm{CH}_{2} \mathrm{Cl}_{2}-$ hexane $(80 / 20, \mathrm{v} / \mathrm{v})$. The aliphatic hydrocarbons were eluted with hexane (F1) and PAHs with the $\mathrm{CH}_{2} \mathrm{Cl}_{2}$-hexane mixture (F2). Silica gel (Aldrich, 70-230 mesh, $60 \AA$ A) was preactivated at $450{ }^{\circ} \mathrm{C}$ for $2 \mathrm{~h}$ and stored at $100{ }^{\circ} \mathrm{C}$ prior to use. $\mathrm{F} 1$ and F2 were evaporated to approximately $50-100 \mu \mathrm{l}$ under nitrogen flux before chromatographic injection.

Hydrocarbons were determined by GC-MS (GCD 1800 A, Hewlett Packard) using a PONA fused silica capillary column, $50 \mathrm{~m} \times 0.20 \mathrm{~mm}$ ID $\times 0.5 \mu \mathrm{m}$ film thickness (Hewlett Packard). The carrier gas was helium $\left(1.0 \mathrm{ml} \cdot \mathrm{min}^{-1}\right)$. The injector temperature was set to $300{ }^{\circ} \mathrm{C}$ and $1 \mu \mathrm{l}$ was injected. The column temperature was programmed from 70 to $300{ }^{\circ} \mathrm{C}\left(5{ }^{\circ} \mathrm{C} \cdot \mathrm{min}^{-1}\right)$ and held for $24 \mathrm{~min}$ at $300{ }^{\circ} \mathrm{C}$. System control and data acquisition were monitored with a HP ChemStation software. The GCD apparatus was operating in the scan mode. The whole analytical procedure was validated using certified sample (marine sediment SRM1941a [NIST]), which is certified for PAHs, whereas aliphatic concentrations are given as non-certified, i.e. indicative (Gonzalez et al., 1999).

\subsubsection{Metal analysis}

The heavy metals measured in each sample were $\mathrm{Fe}, \mathrm{Zn}, \mathrm{Pb}, \mathrm{Cu}$ and $\mathrm{Cd}$. All the materials used for sampling and analysis were cleaned following this procedure: (1) washing with standard detergent and rinsing with deionised water (Milli-Ro, Millipore SA); (2) complete immersion in a $2 \%$ Extran bath during $24 \mathrm{~h}$; (3) rinsing with ultra pure water (18.2 M $\Omega$ Milli-Q water, Millipore SA) and complete immersion in a $10 \% \mathrm{HNO}_{3}$ bath $\left(\mathrm{HNO}_{3} 68 \%\right.$ normapur, Prolabo) during $24 \mathrm{~h}$; (4) rinsing with ultra pure water and drying $24 \mathrm{~h}$ under a class 100 laminar hood; and (5) sealing into a plastic bag. Membranes used for sample filtration (Sartorius, cellulose nitrate, $0.45 \mu \mathrm{m}$ porosity), before trace metal determination, were treated as follows: (1) immersion into a $5 \% \mathrm{HNO}_{3}$ solution during $24 \mathrm{~h}$, (2) rinsing with ultra pure water and storing in a ultra pure water bath.

Acid digestion procedures depended on the type of samples. For deposit samples (GBS, OL and biofilm), approximately 0.5 to $1 \mathrm{~g} \mathrm{dw}$ was digested in a Teflon cup with conc. $\mathrm{HNO}_{3}(18 \mathrm{ml})$ and conc. $\mathrm{HClO}_{4}(2 \mathrm{ml})$. The liquid was evaporated to dryness in a sand bath at $100{ }^{\circ} \mathrm{C}$. The final residue was dissolved using $30 \mathrm{ml}$ of $1 \mathrm{~N} \mathrm{HNO}_{3}$. After a $15 \mathrm{mn}$-centrifugation at $3500 \mathrm{rev} . / \mathrm{min}$, the supernatant was stored at $4{ }^{\circ} \mathrm{C}$ prior to analysis. For 
Table 1

Physico-chemical parameters measured in the different sewer deposits sampled in the 'St. Gilles' trunk (Central Paris)

\begin{tabular}{|c|c|c|c|c|c|c|c|}
\hline \multirow[t]{2}{*}{ Samples } & \multirow[t]{2}{*}{$n$} & \multicolumn{3}{|c|}{ Moisture contents (\%) } & \multicolumn{3}{|c|}{ Volatile solids content $(\%)$} \\
\hline & & $\mathrm{d} 10$ & $\mathrm{~d} 50$ & d90 & $\mathrm{d} 10$ & $\mathrm{~d} 50$ & $\mathrm{~d} 90$ \\
\hline Gross bed sediment & 5 & 29.0 & 32.0 & 41.2 & 5.9 & 6.6 & 10.9 \\
\hline Gross bed sediment $(<400 \mu \mathrm{m})$ & 5 & - & - & - & 6.8 & 7.6 & 8.9 \\
\hline Gross bed sediment $(\geq 400 \mu \mathrm{m})$ & 5 & - & - & - & 5.2 & 7.4 & 8.8 \\
\hline Organic layer & 5 & 74.3 & 85.5 & 90.4 & 38.8 & 51.4 & 70.5 \\
\hline Biofilm & 17 & 87.3 & 90.0 & 92.7 & 55.5 & 60.5 & 67.4 \\
\hline
\end{tabular}

$n$ : number of samples

liquid samples (waste water), an aliquot, typically $500 \mathrm{ml}$ was filtered at $0.45 \mu \mathrm{m}$, in a polyethylene filtration unit in order to separate dissolved and particulate phases. Particulate matter was dried to a constant weight at $40{ }^{\circ} \mathrm{C}$ and digested in the same way as the deposit samples. The filtrate was acidified at $\mathrm{pH} 1$ with conc. $\mathrm{HNO}_{3}$ and stored at $4{ }^{\circ} \mathrm{C}$ prior to analysis.

Dissolved and bulk metals were determined using a flame $(\mathrm{Fe}, \mathrm{Zn}, \mathrm{Pb}, \mathrm{Cu})$ and furnace $(\mathrm{Cd})$ atomic absorption spectrophotometer (Perkin Elmer 1100B) with argon flow (N5.6, Linde Gaz) and deuterium lamp for non-specific absorption correction (matrix effect). For Cd determination, $\mathrm{NH}_{4} \mathrm{H}_{2} \mathrm{PO}_{4}$ (Merck, Suprapur) was added for matrix modification and prevention of $\mathrm{Cd}$ loss by volatilisation.

\section{Results and discussion}

\subsection{Sewer deposit characterisation}

As previously noticed, the bed sediment, accumulated during dry weather flow periods, is generally composed of the GBS and the OL. In the 'St. Gilles' trunk, which is a middle size collector, the depth of GBS was between 5 and $40 \mathrm{~cm}$ (Ahyerre, 1999; Oms et al., 2003) and the OL one was between 2 and $15 \mathrm{~cm}$ (Oms et al., 2003). The third deposit observed in the 'St. Gilles' trunk was the biofilm. It was fixed to the trunk wall at the mean water level all through the collector, i.e. from the 'St. Gilles'- 'Rivoli' junction up to 650 $\mathrm{m}$ upstream. Contents of volatile solids, hydrocarbons (aliphatic and aromatic compounds) and heavy metals measured in these three types of sewer deposits are reported in this section. Concerning the GBS, two-grain size fractions, i.e. inferior and superior to $400 \mu \mathrm{m}$, were considered, GBSi and GBSs, respectively.

\subsubsection{Volatile solid content}

Table 1 shows the physico-chemical parameters measured in the three types of sewer deposits. Firstly, we observe that the humidity content of the GBS was very low compared to the other kinds of deposits. Secondly, these results illustrate that the GBS had an inorganic nature (VSC of $6.6 \%$ ) whereas the OL and the biofilm had an organic nature (VSC of $51 \%$ and $61 \%$, respectively). These results are in good agreement with previous studies carried out in the Paris combined sewer. Indeed, Ahyerre et al. (2000) reported that the median VSC in the GBS, OL and biofilm extrated from the 'Vieille du Temple' trunk ('Le Marais' catchment) were 9.6\%, 68\% and 58\%, respectively. Moreover, a recent research program, focusing on the GBS, exhibited that, at the whole Paris network scale, the median VSC in this sediment only reached $7.2 \%$ (Rocher et al., 2003b). Studies undertaken in other European countries have also underlined these sediment properties. For example, experiments carried out in the United Kingdom (Crabtree, 1989; Arthur, 1996) and in Germany (Ristenpart, 1995; Ristenpart et al., 1995) showed that VSC were between $3 \%$ and $15 \%$ in the GBS and between $50 \%$ and $80 \%$ in the OL, respectively.

\subsubsection{Hydrocarbon contents}

The range of total aliphatic hydrocarbon (TAH) and total PAH contents measured in the different 
Table 2

Values of TAH, PAH and heavy metal contents in the three kinds of combined sewer deposits sampled in the 'St. Gilles' trunk (Central Paris)

\begin{tabular}{|c|c|c|c|c|c|c|c|c|c|c|c|c|}
\hline & \multicolumn{6}{|c|}{ Gross bed sediment $(n=5)$} & \multicolumn{3}{|c|}{ Organic layer $(n=5)$} & \multicolumn{3}{|c|}{ Biofilm $(n=14-17)$} \\
\hline & \multicolumn{3}{|c|}{$<400 \mu \mathrm{m}$} & \multicolumn{3}{|c|}{$\geq 400 \mu \mathrm{m}$} & \multirow[b]{2}{*}{$\mathrm{d} 10$} & \multirow[b]{2}{*}{$\mathrm{d} 50$} & \multirow[b]{2}{*}{ d90 } & \multirow[b]{2}{*}{$\mathrm{d} 10$} & \multirow[b]{2}{*}{$\mathrm{d} 50$} & \multirow[b]{2}{*}{ d90 } \\
\hline & $\mathrm{d} 10$ & $\mathrm{~d} 50$ & d90 & $\mathrm{d} 10$ & $\mathrm{~d} 50$ & d90 & & & & & & \\
\hline \multicolumn{13}{|l|}{ This work } \\
\hline TAH $(\mu \mathrm{g} / \mathrm{g})$ & 24 & 35 & 64 & 21 & 30 & 149 & 55 & 62 & 85 & 119 & 204 & 262 \\
\hline Total PAH $(\mu \mathrm{g} / \mathrm{g})$ & 5.2 & 11.6 & 71.5 & 3.4 & 25.7 & 39.7 & 2.1 & 5.4 & 31.7 & 0.1 & 2.0 & 5.5 \\
\hline $\mathrm{Fe}(\mathrm{mg} / \mathrm{g})$ & 20.2 & 20.9 & 23.2 & 15.9 & 17.7 & 26.2 & 3.8 & 10.0 & 37.2 & 0.9 & 1.8 & 4.0 \\
\hline $\mathrm{Zn}(\mathrm{mg} / \mathrm{g})$ & 1.7 & 1.9 & 2.0 & 1.2 & 1.5 & 2.1 & 1.5 & 1.6 & 1.7 & 0.2 & 0.6 & 1.6 \\
\hline $\mathrm{Pb}(\mathrm{mg} / \mathrm{g})$ & 0.69 & 0.85 & 1.37 & 0.73 & 1.40 & 3.18 & 0.25 & 0.33 & 0.47 & 0.04 & 0.23 & 0.66 \\
\hline $\mathrm{Cu}(\mathrm{mg} / \mathrm{g})$ & 0.56 & 0.61 & 0.79 & 0.15 & 0.28 & 0.43 & 0.20 & 0.22 & 0.26 & 0.04 & 0.14 & 0.41 \\
\hline $\mathrm{Cd}(\mathrm{mg} / \mathrm{g})$ & 0.01 & 0.01 & 0.02 & 0.01 & 0.02 & 0.04 & 0.01 & 0.02 & 0.06 & $<\mathrm{DL}$ & $<\mathrm{DL}$ & $<\mathrm{DL}$ \\
\hline \multicolumn{13}{|c|}{ Previous studies (1994-1999) } \\
\hline \multicolumn{13}{|c|}{ Gonzalez (1) } \\
\hline TAH $(\mu \mathrm{g} / \mathrm{g})$ & - & 32 & 153 & 5 & 35 & 369 & 97 & 125 & 260 & 198 & 268 & 518 \\
\hline Total PAH $(\mu \mathrm{g} / \mathrm{g})$ & - & 2.7 & 6.9 & 0.6 & 3.3 & 9.5 & 0.6 & 2.9 & 8.0 & 0.1 & 0.5 & 17.6 \\
\hline \multicolumn{13}{|l|}{ Garnaud (2) } \\
\hline Zn (mg/g) & 2.6 & 4.3 & 13.9 & 0.5 & 3.0 & 4.4 & - & 1.3 & - & - & 21.4 & - \\
\hline $\mathrm{Pb}(\mathrm{mg} / \mathrm{g})$ & 1.25 & 1.94 & 3.83 & 0.48 & 1.37 & 4.92 & - & 0.21 & - & - & 3.89 & - \\
\hline $\mathrm{Cu}(\mathrm{mg} / \mathrm{g})$ & 0.51 & 0.91 & 2.71 & 0.10 & 0.19 & 0.37 & - & 0.13 & - & - & 2.91 & - \\
\hline $\mathrm{Cd}(\mathrm{mg} / \mathrm{g})$ & 0.002 & 0.005 & 0.013 & 0.001 & 0.002 & 0.002 & - & 0.001 & - & - & 0.013 & - \\
\hline
\end{tabular}

(1) Gonzalez, 2001; Moilleron et al., 2002, (2) Garnaud, 1999.

sewer deposits are summarized in Table 2 and the Fig. 3 illustrates the median values. For TAHs, median contents were estimated at 31, 62 and 204 $\mu \mathrm{g} \cdot \mathrm{g}^{-1} \mathrm{dw}$ in the GBS, OL and biofilm. High TAH amounts in the biofilm and, to a lesser extent, in the OL were probably linked to the biological nature of these two deposits. An opposite trend was observed for PAHs since median contents were $23.3 \mu \mathrm{g} \cdot \mathrm{g}^{-1} \mathrm{dw}$ in the GBS and only 5.4 and $2 \mu \mathrm{g} \cdot \mathrm{g}^{-1} \mathrm{dw}$ in the OL and biofilm. For aliphatic hydrocarbons, our results are in good agreement with previous study carried out in this urban catchment. Indeed, Gonzalez (2001) reported that median TAH contents in GBS, OL and biofilm were 34, 125 and $268 \mu \mathrm{g} \cdot \mathrm{g}^{-1} \mathrm{dw}$. For aromatic hydrocarbons, contamination levels observed in this work are two to seven times higher than those reported by Gonzalez (2001), which ranged from 0.5 to $3.3 \mu \mathrm{g} \cdot \mathrm{g}^{-1} \mathrm{dw}$.

\subsubsection{Heavy metal contents}

The range of heavy metal contents are summarized in Table 2 and Fig. 3 presents the median values. Firstly, this figure underlines that, for the majority of metals, the highest metallic loads between the two kinds of bed deposits were found in the GBS. In this deposit, contents of $\mathrm{Fe}, \mathrm{Zn}$, $\mathrm{Pb}, \mathrm{Cu}$ and $\mathrm{Cd}$ were $18.2 \mathrm{mg} \cdot \mathrm{g}^{-1} \mathrm{dw}, 1.53$ $\mathrm{mg} \cdot \mathrm{g}^{-1} \mathrm{dw}, 1.30 \mathrm{mg} \cdot \mathrm{g}^{-1} \mathrm{dw}, 0.33 \mathrm{mg} \cdot \mathrm{g}^{-1} \mathrm{dw}$ and $0.017 \mathrm{mg} \cdot \mathrm{g}^{-1} \mathrm{dw}$, respectively. Nearly similar contents of $\mathrm{Zn}, \mathrm{Cu}$ and $\mathrm{Cd}$ were measured in the OL $\left(1.58,0.22\right.$ and $\left.0.020 \mathrm{mg} \cdot \mathrm{g}^{-1} \mathrm{dw}\right)$, while $\mathrm{Fe}$ and $\mathrm{Pb}$ contents in OL $\left(10\right.$ and $\left.0.33 \mathrm{mg} \cdot \mathrm{g}^{-1} \mathrm{dw}\right)$ were two to four times lower than the GBS ones. The results here are in good agreement with a previous study carried out in this urban catchment (Garnaud, 1999). Indeed, except for the $\mathrm{Zn}$ load in the GBS $\left(3.2 \mathrm{mg} \cdot \mathrm{g}^{-1} \mathrm{dw}\right)$, which is twice as high as the values here, Garnaud (1999) reported quite similar contamination levels in the GBS (difference below 10\%) and OL (difference below $40 \%$ ) for $\mathrm{Zn}, \mathrm{Pb}, \mathrm{Cu}$ (Table 2).

Secondly, Fig. 3 highlights the significant difference between the metallic loads in these bed deposits and in the biofilm. In this latter, contents of $\mathrm{Fe}, \mathrm{Zn}, \mathrm{Pb}$ and $\mathrm{Cu}$ were only $1.8 \mathrm{mg} \cdot \mathrm{g}^{-1}, 0.6$ $\mathrm{mg} \cdot \mathrm{g}^{-1}, 0.23 \mathrm{mg} \cdot \mathrm{g}^{-1}$ and $0.14 \mathrm{mg} \cdot \mathrm{g}^{-1}$, respec- 


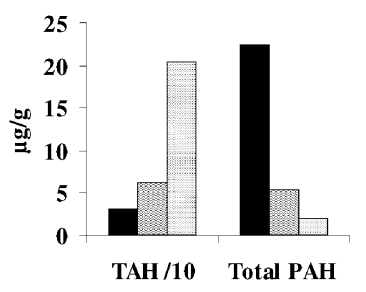

口 GBS

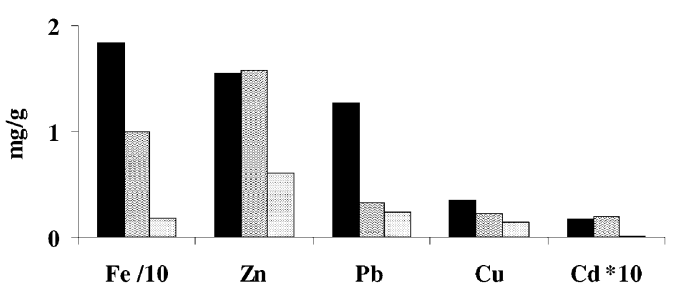

OL

$\square$ Biofilm

Fig. 3. TAH, PAH and heavy metal contents $\left(\mu \mathrm{g} \cdot \mathrm{g}^{-1} \mathrm{dw}\right.$ and $\left.\mathrm{mg} \cdot \mathrm{g}^{-1} \mathrm{dw}\right)$ measured in the gross bed sediment, the organic layer and the biofilm sampled in the 'St. Gilles' collector (Central Paris).

tively. Thus, depending on the metal considered, metal contents in the biofilm were from 2.5 to 10 and 1.4 to 5.5 times smaller than GBS and OL ones, respectively. This result is of prime importance since it proves that, in this type of middle size collectors, there is no phenomenon of metallic accumulation in biofilm. The fact that biofilm does not accumulate metals is probably linked to the hydraulic conditions inside the combined sewer system, i.e. (1) the quite high dry weather flow velocity-between 0.05 and $0.4 \mathrm{~m} \cdot \mathrm{s}^{-1}$ (Oms, 2003) — which tends to inhibit metals passing from waste water to biofilm and (2) the regular occurrence of rain events which induces the biofilm erosion and, consequently, limits its residence time in the collector. The results here invalidate conclusions drawn from the previous experiment led on this catchment (Garnaud, 1999; Chebbo et al., 2001) suggesting that biofilm might strongly accumulate metallic elements (Table 2). It is probable that the differences could be explained by the development of the sampling procedures between these studies. Indeed, a recent research program (Rocher et al., 2003a), focused on the biofilm, has described, using a transmission electronic microscope, the structure of the sewer biofilm and has provided new knowledge required to identify and collect the biofilm in a combined sewer without error.

\subsection{Pollutant stocks in the different kinds of sewer deposits}

Fig. 4 represents the distributions of hydrocarbons and heavy metals between the different sewer deposits in the 'St. Gilles' collector. The pollutant masses stored in each deposit were assessed by multiplying the pollutant loads by dry masses. Deposit masses used for calculation were 13700 $\mathrm{kg}, 2800 \mathrm{~kg}, 1200 \mathrm{~kg}$ and $22 \mathrm{~kg}$ for GBSs, GBSi, $\mathrm{OL}$ and biofilm, respectively. These masses were estimated by Ahyerre (1999) and Oms et al. (2003), who established GBS and OL profiles in the collector 'St. Gilles' using a measuring rod

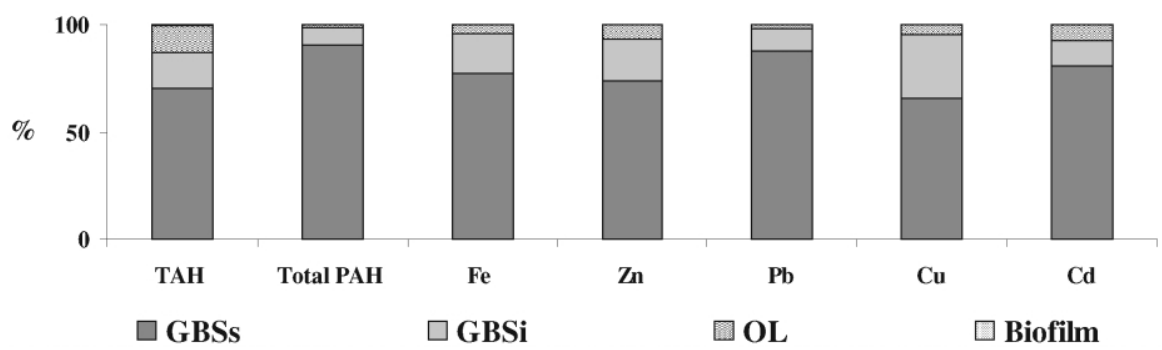

Fig. 4. Distribution of hydrocarbons (TAH and Total PAH) and heavy metals (\%) between the different sewer deposits in the 'St. Gilles' trunk (Central Paris). 
and an endoscope. Whatever the pollutant considered, the highest pollutant mass was found in the GBS. Percentages of TAHs and PAHs stored in the GBS reached $87 \%$ and $98 \%$ of the total insewer stock, respectively. Percentages of Fe, Zn, $\mathrm{Pb}, \mathrm{Cu}$ and $\mathrm{Cd}$ in this deposit were $96 \%, 93 \%$, $98 \%, 96 \%$ and $92 \%$ of the total in-sewer stock, respectively. Moreover, a great part of the hydrocarbon and heavy metal pollutants was fixed to the coarse particles of the GBS $(>400 \mu \mathrm{m})$. TAHs, PAHs and heavy metals associated to this coarse fraction represented $70 \%, 90 \%$ and from $66 \%$ to $87 \%$ of the total in-sewer stock, respectively. Remaining pollutants were mainly stored in the OL. Indeed, TAHs, PAHs and heavy metals contained in this layer represented $13 \%, 2 \%$ and from $2 \%$ to $8 \%$ of the total in-sewer stock, respectively. Hence, pollutant stocks in the biofilms were much smaller than for the GBS and OL. Whatever the pollutant considered, the portion of pollutants stored in the biofilms was lower than $1 \%$ of the total in-sewer stock.

\subsection{Sewer deposits as potential wet weather pol- lution sources}

A previous study showed that, during rain events, an important part of pollution originates from in-sewer sources, i.e. coming from the bed deposit resuspension and the biofilm erosion (Gromaire, 1998). The main mechanism involved is the shear stress resulting from the increased velocities under storm flow conditions (Crabtree et al., 1995; Michelbach, 1995; Ahyerre et al., 2000). Recent studies have established that the OL was the main source of eroded solids (Ristenpart et al., 1995; Ahyerre et al., 2000; Chebbo et al., 2001). In the work described here, to approximately assess the contribution of the different kinds of sewer deposits to the wet weather pollution, it was assumed that (1) the GBS was not resuspended, (2) the OL was entirely resuspended and (3) the biofilm was entirely eroded. These hypotheses were accepted even if, in fact, the GBS might be partially eroded, a little part of the OL might resist resuspension and a part of the biofilm might resist erosion (Arthur et al., 1996; Ahyerre, 1999). Admitting these hypotheses, the OL contribution to TAH and PAH pollution reached $94 \%$ and $99 \%$ of the total in-sewer pollution, respectively, while the biofilm contribution was only $6 \%$ and $1 \%$, respectively. A similar trend was observed for metals since, whatever the metal considered, the OL contribution to metallic pollution was above $98 \%$ of the total in-sewer pollution whereas the biofilm contribution was below $2 \%$. These results emphasize that, at the 'Le Marais' catchment scale, the biofilm was not an important source of wet weather pollution and can be disregarded.

\subsection{Pollutant fingerprints in the different sewer deposits}

\subsubsection{Aliphatic hydrocarbons}

More than 20 resolved hydrocarbons or $n$ alkanes, i.e. from $n$-C10 to $n$-C 33 , have been identified in the different samples. In addition, pristane (Prist) and phytane (Phyt), two isoprenoids, were also regularly observed. Fig. 5 illustrates the distributions of $n$-alkanes and isoprenoids in the sewer deposit (GBS, OL and biofilm) and waste water (SS and DP) samples. Concerning sewer deposits, the GBS showed an aliphatic distribution pattern very different to the other deposits. The aliphatic distribution patterns of the two GBS fractions (GBSi and GBSs) were centred on $n$-C18 and most of $n$-alkanes were light compounds (carbon number $\leq 20$ ). The light/heavy molecular weight hydrocarbon ratios (LMW/ HMW), estimated at 1.4 and 2.2 for the GBSi and the GBSs, respectively, underlined the predominance of light compounds (Table 3). The other deposits, i.e. the OL and the biofilm, exhibited a distribution pattern mainly peaked at around $n$ C29. Contrary to the GBS case, heavy compounds (carbon number $>20$ ) were predominant since the LMW/HMW ratios were calculated at 0.5 and 0.4 for OL and biofilm, respectively, (Table 3). The heavy $n$-alkane predominance in OL and biofilm has been already noticed in the 'Le Marais' combined sewer, since Gonzalez (2001) reported that heavy compounds represented more than $60 \%$ and $85 \%$ of TAHs in OL and biofilm, respectively.

\subsubsection{Aromatic hydrocarbons}

All samples were analysed for the 16 PAHs from the US-EPA list and their alkylated deriva- 
a)

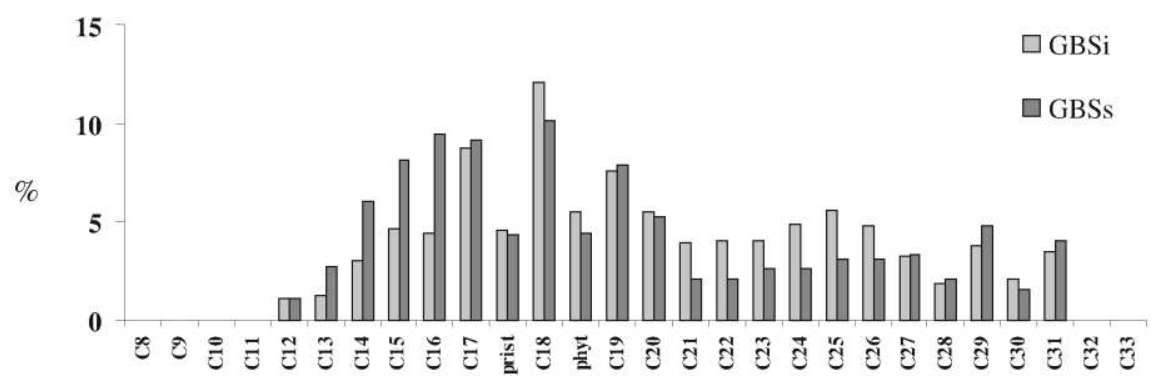

b)

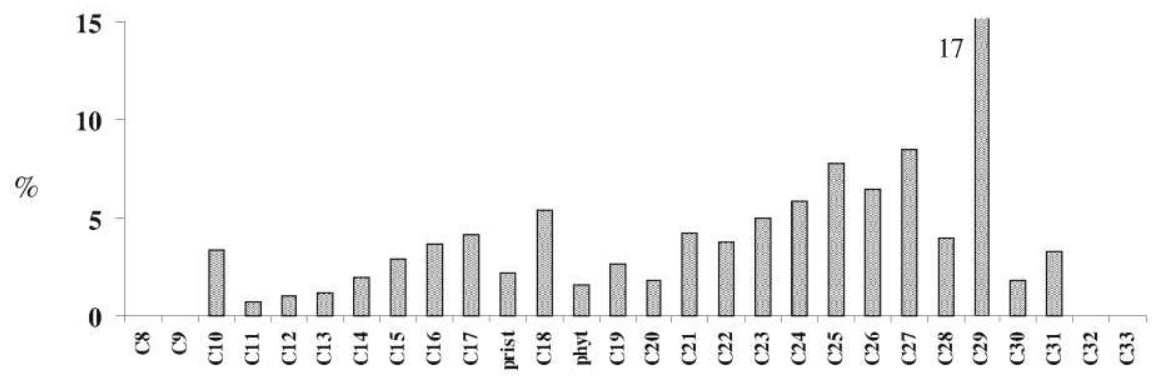

c)

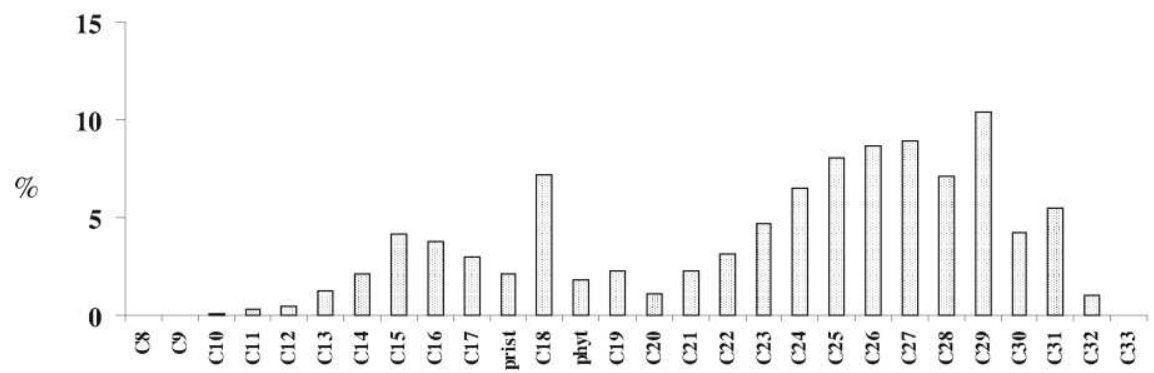

d)

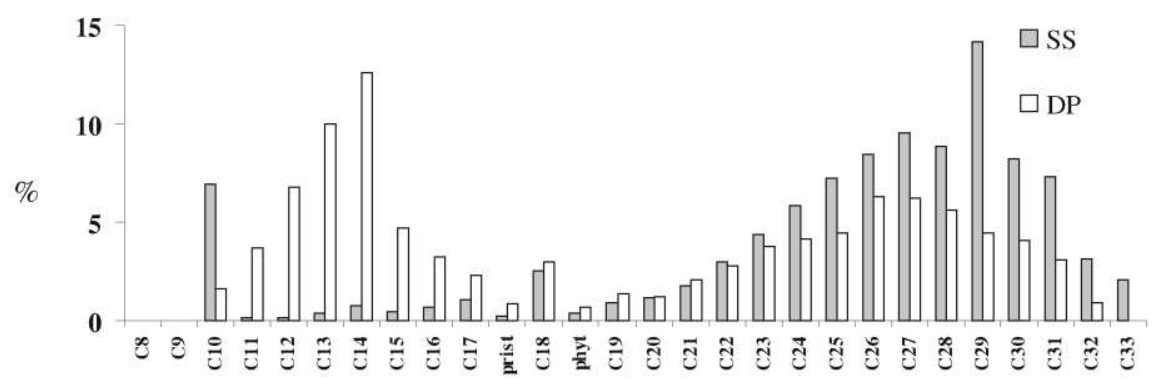

Cn values ( $n=8$ to 33 ) represent the 26 n-alkanes measured during this study; $n$ refers to the carbon number of the linear chain.

Fig. 5. Distributions of $n$-alkanes and isoprenoids (\%) in (a) the gross bed sediment (grain size fractions above and below 400 $\mu \mathrm{m}$ ), (b) the organic layer, (c) the biofilm and (d) the waste water (suspended solids and dissolved phase) sampled in the 'St. Gilles' trunk (Central Paris).

tives. Fig. 6 illustrates the PAH distributions in all the sewer deposits and in the waste water. Global PAH distribution patterns were nearly similar for all the deposits, i.e. characterised by an abundance of heavy compounds. Values of the light molecular weight PAH (2-3 rings)/heavy molecular weight PAH (4-6 rings) ratios (LMW/HMW) were 0.26, $0.22,0.23,0.25$ for GBSi, GBSs, OL and biofilm, 
Table 3

Values of alkane and PAH indices for the three kinds of sewer deposits and the waste water (suspended solids and dissolved phase) sampled in the 'St. Gilles' trunk (Central Paris)

\begin{tabular}{|c|c|c|c|c|c|c|}
\hline & \multicolumn{4}{|c|}{ Combined sewer deposits } & \multicolumn{2}{|l|}{ Waste water } \\
\hline & \multicolumn{2}{|c|}{ Gross bed sediment } & \multirow{2}{*}{$\begin{array}{l}\text { Organic } \\
\text { layer }\end{array}$} & \multirow[t]{2}{*}{ Biofilm } & \multirow{2}{*}{$\begin{array}{l}\text { Suspended } \\
\text { solids }\end{array}$} & \multirow{2}{*}{$\begin{array}{l}\text { Dissolved } \\
\text { phase }\end{array}$} \\
\hline & $<400 \mu \mathrm{m}$ & $\geq 400 \mu \mathrm{m}$ & & & & \\
\hline \multicolumn{7}{|l|}{ Alkanes } \\
\hline МAH & $\mathrm{C} 18$ & $\mathrm{C} 18$ & $\mathrm{C} 29$ & $\mathrm{C} 29$ & $\mathrm{C} 29$ & $\mathrm{C} 14$ \\
\hline$\% \mathrm{MAH}$ & 12 & 10 & 17 & 10 & 14 & 13 \\
\hline LMW/HMW & 1.4 & 2.2 & 0.5 & 0.4 & 0.2 & 1.1 \\
\hline $\mathrm{UCM}(\mu \mathrm{g} / \mathrm{g}$ or 1$)$ & 433 & 218 & 463 & 1571 & 3742 & 247 \\
\hline $\mathrm{UCM} / \mathrm{R}$ & 14.9 & 6.0 & 7.2 & 8.9 & 6.0 & 5.4 \\
\hline $\mathrm{CPI}$ & 1.1 & 1.1 & 1.5 & 1.1 & 1.0 & 0.9 \\
\hline Prist/Phyt & 0.8 & 1.0 & 1.4 & 1.2 & 0.6 & 1.2 \\
\hline C17/Prist & 1.9 & 2.1 & 1.9 & 1.4 & 4.5 & 2.7 \\
\hline C18/Phyt & 2.2 & 2.3 & 3.5 & 3.9 & 6.8 & 4.3 \\
\hline n-alkanes/C16 & 23 & 11 & 27 & 26 & 140 & 31 \\
\hline $\mathrm{C} 17 / \mathrm{C} 29$ & 2.3 & 1.9 & 0.2 & 0.3 & 0.1 & 0.5 \\
\hline \multicolumn{7}{|l|}{ PAHs } \\
\hline MPAH & Pyr & Fluo & Fluo & Pyr & $\mathrm{P}$ & $\mathrm{P}$ \\
\hline \%МРАН & 40 & 40 & 43 & 67 & 100 & 60 \\
\hline LMW/HMW & 0.26 & 0.22 & 0.23 & 0.25 & - & - \\
\hline Alk./Par. & 0.07 & 0.09 & 0.0 & 0.0 & 0.0 & 0.0 \\
\hline
\end{tabular}

For alkanes: $\mathrm{MAH}=$ major aliphatic hydrocarbon; $\mathrm{LMW} / \mathrm{HMW}=$ light molecular weight $(\leq 20$ carbons $) /$ high molecular weight ( $>20$ carbons); $\mathrm{UCM}=$ unresolved complex mixture; $\mathrm{CPI}=$ carbon preference index. For PAHs: $\mathrm{MPAH}=\mathrm{major} \mathrm{PAH}$; LMW $/$ HMW = light molecular weight PAHs (2-3 rings)/high molecular weight PAHs (4-6 rings); Alk./Par. =alkylated derivatives/parent compounds.

respectively, (Table 3). A similar trend was observed in the combined sewer system of Bad Mergentheim (Germany), since Michelbach and Wöhrle (1993) reported that heavy PAHs accounted for more than 80 and $90 \%$ of total PAHs in sewer sediment and biofilm. Moreover, whatever the deposits considered, phenanthrene $(\mathrm{P})$, fluoranthene (Fluo) and pyrene (Pyr) were identified as the most abundant compounds since their sums accounted for 95, 89, 100 and $100 \%$ of total PAHs in the GBSi, GBSs, OL and biofilm. Nevertheless, the two fractions of GBS were distinguishable

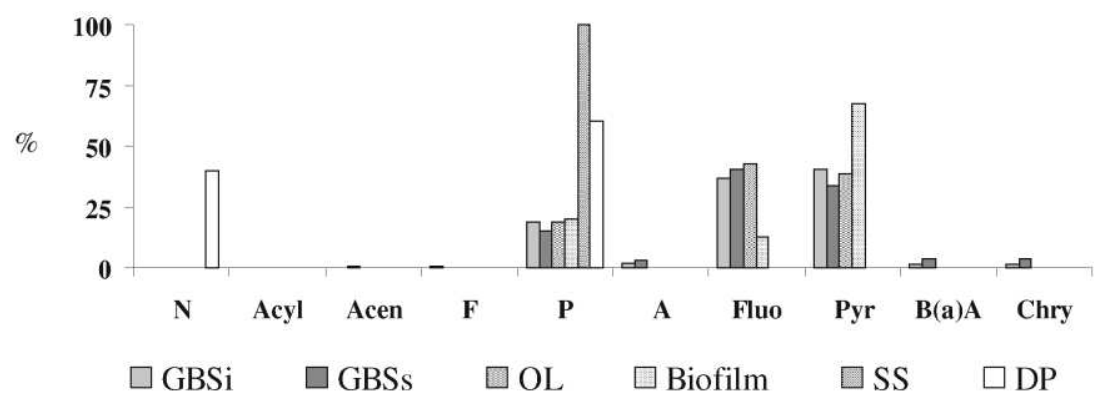

N: Naphtalene, Acyl: Acenaphthylene, Acen: Acenaphthene, F: Fluorene, P: Phenanthrene, A: Anthracene, Fluo: Fluoranthene, Pyr: Pyrene, B(a)A: Benzo[a]Anthracene, Chry: Chrysene

Fig. 6. PAH distributions ( $\%$ in the gross bed sediment (grain size fractions above and below $400 \mu \mathrm{m}$ ), the organic layer, the biofilm and the waste water (suspended solids and dissolved phase) sampled in the 'St. Gilles' collector (Central Paris). 


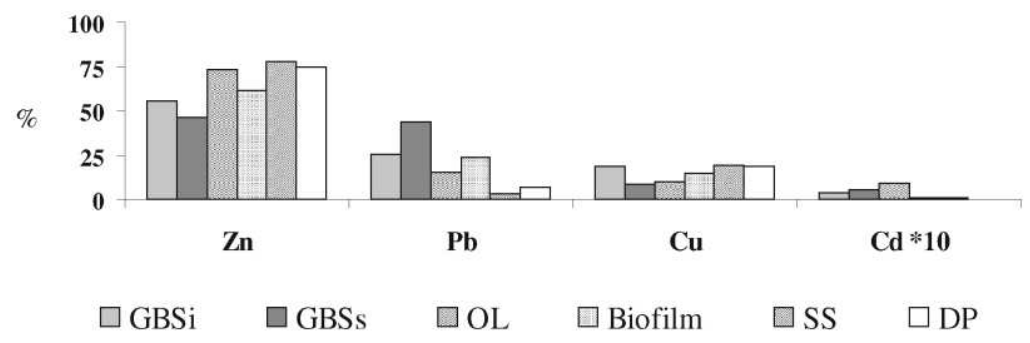

Fig. 7. Heavy metal distributions (\%) in the gross bed sediment (grain size fractions above and below $400 \mu \mathrm{m}$ ), the organic layer, the biofilm and the waste water (suspended solids and dissolved phase) sampled in the 'St. Gilles' collector (Central Paris).

from the other deposits by (1) the presence of other heavy PAHs such as anthracene (A), benzo $[a]$ anthracene $(\mathrm{B}(a) \mathrm{A})$ and chrysene (Chry) and (2) the presence of alkylated derivatives illustrated by alkylated derivative/parent compound ratios of 0.07 and 0.09 for the GBSi and GBSs, respectively.

\subsubsection{Metal fingerprints}

Five heavy metals ( $\mathrm{Fe}, \mathrm{Zn}, \mathrm{Pb}, \mathrm{Cu}$ and $\mathrm{Cd}$ ) were measured in all samples. Fig. 7 illustrates the metallic distributions in the sewer deposits and waste water without taking into account the major crustal element: Fe. Fe was excluded from this representation because of its strong predominance, which is harmful to the graphic readability. Indeed, the relative part of this crustal element was above $80 \%$ of the total metals in bed deposits and was nearly $65 \%$ of the total metals in biofilm. Whatever the deposit considered, $\mathrm{Zn}$ was identified as the most abundant metal. In the gross sediment, $\mathrm{Zn}$ proportion was estimated at $56-46 \%$ of the total metals for GBSi-GBSs, respectively. Predominance of this element was much more marked in the other deposits, since $\mathrm{Zn}$ accounted for $73 \%$ and $62 \%$ of the total metals for OL and biofilm, respectively. $\mathrm{Zn}$ predominance in sewer deposits has already been noticed by several authors. Thus, Garnaud (1999) reported that $\mathrm{Zn}$ represented 60$66 \%, 79 \%$ and $76 \%$, respectively, of the total metals for GBSi-GBSs, OL and biofilm extracted from the Paris combined sewer. High proportion of $\mathrm{Zn}$ in sewer deposits was also observed in other European countries. For example, Michelbach and Wöhrle (1993) showed that Zn accounted for 85 and $87 \%$ of the total metals in sewer sediment and biofilm extracted from the combined sewer of Bad
Mergentheim (Germany). Besides the Zn predominance, metal distributions in all the sewer deposits were characterised by the presence of $\mathrm{Pb}$ and $\mathrm{Cu}$. In the GBS, the relative part of $\mathrm{Pb}$ was important as it reached $26-44 \%$ of the total metals for GBSiGBSs. In the other deposits, this proportion was slightly lower since it was assessed at 15 and 24\% of total metals in OL and biofilm. Contrary to the $\mathrm{Pb}$ case, relative parts of $\mathrm{Cu}$ were nearly similar in all kinds of sewer deposits, i.e. between 9 and $18 \%$ of the total metals. These results are in good agreement with a previous study carried out in the Paris sewer network where Garnaud (1999) reported that the relative part of $\mathrm{Pb}$ was $27-30 \%, 13 \%$ and $14 \%$, respectively, of total metals in GBSiGBSs, OL and biofilm and the relative part of $\mathrm{Cu}$ was between 4 and $13 \%$ of total metals in all sewer deposits.

\subsection{Hydrocarbon origins in the different sewer deposits}

The aliphatic and aromatic hydrocarbon distributions differ according to the production sources. The evaluation of $n$-alkane and PAH distribution indexes in sewer sediments helped to elucidate the origins of complex hydrocarbon mixtures. The $n$ alkane indexes allowed the identification of biogenic and petrogenic sources while $\mathrm{PAH}$ ratios were sensitive indicators of petrogenic and pyrogenic inputs.

\subsubsection{Aliphatic hydrocarbons}

The analysis of aliphatic distributions in the different sewer (Fig. 5a-c) was carried out using indexes presented in Table 3. The major aliphatic 
hydrocarbon (MAH) was $n$-C18 in the GBS and $n-\mathrm{C} 29$ in the OL and the biofilm. Abundance of $n$-C18 in the GBS indicated that this sediment was affected by the impact of petroliferous derivatives (oils) (Colombo et al., 1989) while abundance of $n$-C29 in the OL and biofilm was attributed to biogenic inputs, i.e. terrestrial plants and faecal matter (Moreda et al., 1998). Moreover, LMW/ HMW values were found to be higher than 1.4 in GBS and lower than 0.5 in the OL and biofilm (Table 3). These results confirm the MAH index since the petroleum contamination is characterised by a ratio higher than unity and the biogenic contamination leads to a ratio lower than unity (Colombo et al., 1989; Moreda et al., 1998). Distinction between biogenic and petrogenic origins can be carried out using the odd/even $n$ alkane predominance. This odd/even predominance can be quantitatively formulated by different specific indexes such as the $n$-C16 ratio (sum of $n$-alkanes $/ n$-C16) or the carbon preference index (CPI) defined as the weighted ratio of odd to even carbon-numbered $n$-alkanes in the range $n$-C10 to $n$-C 33 . The $n$-C16 ratio is usually large (approx. 50) in biogenic samples due to the dominance of odd $n$-alkanes and is smaller (approx. 15) in petrogenic samples (Colombo et al., 1989). A value of CPI near unity is typical to petrogenic origin while a greater value (i.e. above 4-5) indicates a biogenic origin (Bomboi and Hernández, 1990; Bouloubassi and Saliot, 1993; Wang et al., 1997). Table 3 shows that the OL and biofilm were characterised by values of $n-\mathrm{C} 16$ ratio (27 and 26, respectively) greater than for the GBS (23 and 11 for GBSi and GBSs). In the same way, the CPI value of the OL was calculated at 1.5 whereas for GBS it was 1.1. Surprisingly, the CPI value of the biofilm was equal to that for GBS. Thus, except for the CPI value for biofilm, these two indices confirmed the impact of the biogenic contamination in the OL-biofilm and the petrogenic contamination in the GBS. Nevertheless, the values of these origin indices obtained for the OL and biofilm were lower than those typically attributed to exclusive biogenic impacts ( $n$-C16 ratio $\approx 50, \mathrm{CPI}>4-5)$. This reflects the admixture of petrogenic $n$-alkanes, with low odd/even predominance, in these two sewer deposits.
Gas chromatographic traces of aliphatic hydrocarbons were also characterised by an unresolved complex mixture (UCM), i.e. the hump under the baseline on a chromatographic trace. This unresolved portion is generally considered as a mixture of many structurally complex isomers and homologous of branched and cyclic alkanes (Bouloubassi and Saliot, 1993; Aboulkassim and Simoneit, 1996). The presence of an important UCM in the aliphatic hydrocarbon chromatograms has a wellknown linkage to a contamination by petrogenic hydrocarbons (Colombo et al., 1989). Thus, the absolute UCM content or, alternatively, its relative importance expressed as the ratio of unresolved to resolved compounds (UCM/R) is commonly used as a diagnostic criteria of pollutant origins. In all sewer deposits, UCM was by far the major component of the aliphatic fraction (resolved compounds + UCM). Depending on the sewer deposits, UCM contents varied from 220 to $1570 \mu \mathrm{g} \cdot \mathrm{g}^{-1}$ $\mathrm{dw}$, which accounted for $88-93 \%$ of the total aliphatic fraction, and UCM/R ratios showed values in the range 6-15 (Table 3). These high index values underlined the presence of petroleum contamination since, according to the literature, values below 0.1 indicate a biogenic contamination whereas values above 2 indicate petrogenic inputs (Simoneit, 1989; Aboulkassim and Simoneit, 1995; Bouloubassi and Saliot, 1993). Finally, compositions of aliphatic fractions were different in the GBS and in the OL-biofilm. The aliphatic distribution pattern was indicative of predominant petroleum input in the GBS and reflected a mixture of biogenic and petroleum inputs in the $\mathrm{OL}$ and the biofilm.

\subsubsection{Aromatic hydrocarbons}

The aromatic compound distributions differ according to the production sources. The fingerprints of PAHs from pyrolytic or petrogenic origins are different. These differences may be used to elucidate the PAH origins by using various indices presented in Table 3. As previously shown, the global PAH distribution patterns were nearly similar for all deposits, i.e. characterised by the predominance of heavy PAHs. This predominance, underlined by the LMW/HMW ratio values below 0.3 , indicated pyrolytic origins for PAHs found in 
sewer deposits (Soclo et al., 2000). In the same way, P, Pyr and Fluo, which were previously identified as the most abundant PAHs in all deposits, were considered as typical pyrolytic products derived from high-temperature condensation of lower molecular weight aromatic compounds (Khalili, 1995; Soclo et al., 2000). In the GBS case, the impact of pyrolytic contamination was also suggested by the presence of Chry and $\mathrm{B}(a) \mathrm{A}$, which are considered as markers of combustion processes (Moreda et al., 1998; Soclo et al., 2000). Nevertheless, the presence of alkylated derivatives in the GBS could reflect the admixture of petroleum aromatic compounds since many authors consider that the presence of alkylated homologues is a typical feature of petroleum derivatives (Bomboi and Hernández, 1991; Bouloubassi and Saliot, 1993; Aboulkassim and Simoneit, 1995; Notar et al., 2001).

\subsection{Deposit dynamic in combined sewer}

\subsubsection{Sewer deposit formation}

The objective of this section was to describe the formation processes of the different kinds of sewer deposits. The study of deposit formation was performed by comparing suspended solids pollutant fingerprints with those for sewer deposits. Concerning hydrocarbon pollutants, the aliphatic fraction was only considered since $\mathrm{PAH}$ distributions in SS-P accounted for $100 \%$ of total PAHs-did not provide relevant information.

\subsubsection{Organic layer and biofilm formation. Fig.}

$5 \mathrm{~d}$, which represents the $n$-alkane distributions in the SS and the DP of the waste water flow, shows that SS had an aliphatic distribution pattern very similar to the OL and biofilm ones. Indeed, as for OL and biofilm, the aliphatic distribution in SS was characterised by an abundance of heavy compounds $(\mathrm{LMW} / \mathrm{HMW}=0.2)$ and, especially, by a strong predominance of $n$-C29 (14\% of TAHs) (Table 3). The metal distribution in SS was also found to be close to OL and that for biofilm (Fig. 7). $\mathrm{Zn}$ was largely predominant $(77 \%$ of total metals) and $\mathrm{Cu}$ part was in the same order of magnitude as the OL and for biofilm $(15 \%$ of total metals). Nevertheless, contrary to what was found in sewer deposits, SS exhibited a metal distribution with a very low $\mathrm{Pb}$ percentage ( $3 \%$ of total metals).

Similarities between the SS, OL and biofilm pollutant fingerprints suggest that the SS were the major components of OL and biofilm. It is possible to assume that, during dry weather flow periods, (1) a part of SS going through the combined sewer settles and leads to the OL accumulation and (2) a small part of SS is fixed to the rough surface of sewer trunk at the mean water level and leads to the biofilm formation. However, SS coming from domestic activities are probably not the only components of OL and biofilm since, as previously noticed, pollutant fingerprints in these two deposits reflected the admixture of anthropic pollutants. Thus, it may be assumed that anthropic pollutant loads may be mainly conveyed into Paris combined sewers by street cleaning waters. Indeed, in Paris, like in many big cities, significant human and financial efforts are devoted to the cleaning of streets in order to control litter and to provide suitable aesthetic and sanitary conditions. In this catchment, street fountains are opened everyday in order to wash the gutter and, from two to five times a week, the sidewalks and gutters are washed with pressurised water jets.

3.6.1.2. Gross bed sediment formation. Aliphatic hydrocarbon and metal distributions in the GBS were very different to the other deposits and in the SS. These differences demonstrate that the GBS does not originate from the dry weather sedimentation of SS. Pollutant fingerprints in GBS, indicative of petroleum and pyrolytic origins, suggest that urban runoff (streets and roofs) and street cleaning constitute the main transport mechanism that introduces pollutants into the GBS. Therefore, it is possible to assume that some of the particlesthe setteable part-introduced by urban runoff and street-cleaning waters is deposited in combined sewer leading to the GBS accumulation.

\subsubsection{Storage times of deposits in sewer}

In combined sewers, the occurrence of hydrocarbon pollutant degradation causes modifications 
in the hydrocarbon distribution pattern. The extent of these compositional changes mainly depends on the residence time of the hydrocarbon pollutants in the sewer network. Therefore, the degradation degree can provide information about the residence time of the different deposits in a combined sewer.

Aliphatic hydrocarbon fingerprints are generally used as indicators of the changes in chemical composition due to weathering because they are less degradation resistant than PAHs. Among the various $n$-alkane indexes, $n$-alkane/isoprenoid ratios ( $n$-C17/Prist and $n$-C18/Phyt) are commonly used to evaluate the biodegradation of $n$-alkane mixtures. Indeed, the isoprenoids being degraded at a slower rate in comparison to $n$-alkanes, low values for the $n$-alkane/isoprenoid ratios indicate the presence of degraded aliphatic hydrocarbons (Colombo et al., 1989; Wang et al., 1994). The ratio used in this study was $n$-C18/Phyt (Table 3 ). As expected, SS, which were recently introduced into the combined sewer by way of domestic effluents, exhibited a high ratio value $(n-\mathrm{C} 18 /$ Phyt $=6.8$ ). All the deposits showed $n$-C18/Phyt values lower than in the SS reflecting that degradation processes have occurred in these deposits. Nevertheless, the degradation degree differed depending on the deposit considered. $\mathrm{N}$-alkanes in OL and biofilm, characterised by ratio values of 3.5 and 3.9, respectively, were clearly less degraded than $n$-alkanes in GBSi and GBSs characterised by ratio values of 2.2 and 2.3 .

These results emphasize that the residence times of the OL and biofilm in the combined sewer are quite short. These low residence times are linked to the regular occurrence of rain events, which induce the OL resuspension and the biofilm erosion. On the contrary, the high degradation degree of the aliphatic hydrocarbons in the GBS showed that this coarse sediment is stored a very long time in the combined sewer. It is possible to assume that the most setteable part of the GBS is retained in the middle-sized collector sewers and is only removed by regular operations of sewer pipe maintenance.

\section{Conclusion}

This research program focused on the hydrocar- bon and metallic pollution fixed to the different sewer deposits and has provided new data on the contaminant storage in a Paris combined sewer. Firstly, measurements of hydrocarbon and metal contents in the three kinds of deposits have determined the contaminant distribution between GBS, OL and biofilm. For all pollutants, the major part was stored in GBS (87-98\%), a lesser part in the OL $(2-13 \%)$ and an insignificant part in the biofilm (below 1\%). According to these results, at the 'Le Marais' catchment scale, the potential contribution of the biofilm to wet weather pollution can be considered as negligible compared to the OL contribution. Secondly, hydrocarbon fingerprints were investigated in each deposit in order to elucidate the contamination origins. Aliphatic hydrocarbon distributions were indicative of prominent petroleum inputs in the GBS and reflected a mixture of biogenic and petroleum inputs in the $\mathrm{OL}$ and the biofilm. Aromatic hydrocarbon distributions, characterised by the predominance of $\mathrm{P}$, Pyr and Fluo, suggested an important pyrolytic contamination in all deposits. Finally, the deposit dynamics in the combined sewer were studied by comparing pollutant fingerprints in suspended solids and in sewer deposits. Suspended solids coming from domestic activities were identified as the major component of OL and biofilm while urban runoff and street cleaning seemed to be the main transport mechanism that introduced pollutants into the GBS. Moreover, an evaluation of aliphatic hydrocarbon degradation showed that the residence times in the combined sewer for OL and biofilm were quite short compared to times for the GBS.

These results provide a complete overview of hydrocarbon and metallic pollution accumulated in these combined sewer deposits during dry weather flow periods. This knowledge is needed to better understand the role of sewer deposits as contributors to spilled pollutants from CSOs. The next step of this work is to study the pollutant loads conveyed by the different inputs to the sewer, i.e. road and roof runoff and the sewer effluents (domestic waste water, industrial effluents, etc.). This investigation is expected to guide new strategies, which aim at reducing in-sewer pollution stocks. 


\section{Acknowledgments}

The authors would like to thank Claire Oms (Cereve) for her scientific support during this research project.

\section{References}

Aboulkassim T, Simoneit B. Aliphatic and aromatic hydrocarbons in particulate fallout of Alexandria, Egypt: sources and applications. Environ Sci Technol 1995;29(10):2473-2483.

Aboulkassim T, Simoneit B. Lipid geochemistry of superficial sediments from the coastal environment of Egypt I. Aliphatic hydrocarbons characterization and sources. Mar Chem 1996;54:135-158.

Ahyerre M. Mass balances and transport mechanisms of organic pollution in combined sewers. Environmental Science and Technology Ph D. Thesis, Ecole Nationale des Ponts et Chaussées 1999. p. 209.

Ahyerre M, Chebbo G, Saad M. Sources and erosion of organic solids in a combined sewer line. Urban Water 2000;2(4):305-325.

Arthur S. Near bed solids transport in combined sewers. Ph D. Thesis, University of Albertay Dundee 1996. p. 204.

Arthur S, Ashley RM, Nalluri C. Near bed solids transport in sewers. Water Sci Technol 1996;33(9):69-76.

Bachoc A. Solid transfer in combined sewer networks. Ph D. Thesis, Institut National Polytechnique de Toulouse 1992. p. 281.

Bomboi MT, Hernández A. Distribution of hydrocarbon concentration from urban runoff. Sci Total Environ 1990;93:465-480.

Bomboi MT, Hernández A. Hydrocarbons in urban runoff: their contribution to the wastewaters. Water Res 1991;25(5):557-565.

Bouloubassi I, Saliot A. Investigation of anthropogenic and natural organic inputs in estuarine sediments using hydrocarbon markers (NAH, LAB, PAH). Oceanol Acta 1993;16(2):145-161.

Chebbo G. Solids in urban wet weather discharges: characteristics and treatability. Environmental Science and Technology Ph D. Thesis, Ecole Nationale des Ponts et Chaussées 1992. p. 410.

Chebbo G, Gromaire MC, Ahyerre M, Garnaud S. Production and transport of urban wet weather pollution in combined sewer systems: the 'Le Marais' experimental urban catchment in Paris. Urban Water 2001;3:3-15.

Colombo JC, Pelletier E, Brochu C, Khalil M. Determination of hydrocarbon sources using n-alkane and polyaromatic hydrocarbon distribution indexes. Case study: Rio de la Plata estuary, Argentina. Environ Sci Technol 1989;23:888894.

Crabtree RW. Sediments in sewers. J Inst Water Environ Manage 1989;3:569-578.
Crabtree RW, Ashley R, Gent R. Mousetrap: modelling of real sewer sediment characteristics and attached pollutants. Water Sci Technol 1995;31(7):43-50.

Garnaud S. Transfer and evolution of the metallic pollution in an urban catchment area. Environmental Science and Technology Ph D. Thesis, Ecole Nationale des Ponts et Chaussées 1999. p. 396.

Gonzalez A, Garnaud S, Carpentier S, Moilleron R, Thévenot D. Significance of dissolved and particulate metal and hydrocarbon determinations in urban runoff samples. Proceedings of the 8th International Conference on Urban Storm Drainage, Sydney (Australia); 1999. 4: pp. 1816-1824.

Gonzalez A. Transport and distribution of aliphatic and aromatic hydrocarbons in the 'Le Marais' experimental catchment in Paris centre. Ph D. Thesis, University Paris XII 2001. p. 206.

Gromaire MC. Urban wet weather pollution in combined sewer systems: origins and characteristics. Environmental Science and Technology Ph D. Thesis, Ecole Nationale des Ponts et Chaussées 1998. p. 507.

Gromaire MC, Garnaud S, Saad M, Chebbo G. Contribution of different sources to pollution of wet weather flows in combined sewers. Water Res 2001;35(2):521-533.

Khalili NR. PAH fingerprints for coke ovens, diesel and gasoline engines, highway tunnels and wood combustion emissions. Atmos Environ 1995;29(4):533-542.

Krejci V, Dauber L, Gujer W. Contribution of different sources to pollutant loads in combined sewers. Proceedings of the 4th International Conference on Urban Storm Drainage, Lausanne (Switzerland); 1994. pp. 34-39.

Michelbach S, Wöhrle C. Setteable solids in a combined sewer system, settling characteristics, heavy metals, efficiency of storm water tanks. Water Sci Technol 1993;27(5-6):153164.

Michelbach S. Origin, resuspension and settling characteristics of solids transported in combined sewage. Water Sci Technol 1995;31(7):69-76.

Moilleron R, Gonzalez A, Chebbo G, Thévenot DR. Determination of aliphatic hydrocarbons in urban runoff samples from the 'Le Marais' experimental catchment in Paris centre. Water Res 2002;36:1275-1285.

Moreda JM, Arranz A, Fdez De Betono S, Cid A, Arranz JF. Chromatographic determination of aliphatic hydrocarbons and polyaromatic hydrocarbons (PAHs) in a sewage sludge. Sci Total Environ 1998;220:33-43.

Notar M, Leskovsek H, Faganeli J. Composition, distribution and sources of polycyclic aromatic hydrocarbons in sediments of the gulf of Triest, Northern Adriatic sea. Mar Pollut Bull 2001;42(1):36-44.

Oms C. Nature, location and dynamic of the water-sediment interface in combined sewer. Environmental Science and Technology Ph D. Thesis, Ecole Nationale des Ponts et Chaussées. 2003. p. 150.

Oms C, Gromaire MC, Chebbo G. In-situ observation of the water-sediment interface in combined sewer using endoscopy. Water Sci Technol 2003;47(4):11-18. 
Ristenpart E. Sediment properties and their changes in a sewer. Water Sci Technol 1995;31(7):77-83.

Ristenpart E, Ashley RM, Uhl M. Organic near-bed fluid and particulate transport in combined sewer. Water Sci Technol 1995;31(7):61-68.

Rocher V, Azimi S, Moilleron R, Chebbo G. Biofilm in combined sewer: wet weather pollution source or/and dry weather pollution indicator? Water Sci Technol 2003a;47(4):35-43.

Rocher V, Garnaud S, Moilleron R, Chebbo G. Hydrocarbon pollution fixed to combined sewer sediment: a case study in Paris. Chemosphere 2003b. In press.

Simoneit BRT. Organic matter of the troposphere-V: Application of molecular marker analysis to biogenic emissions into the troposphere for source reconciliations. J Atmos Chem 1989;8:251-275.

Soclo HH, Garrigues P, Ewald M. Origin of polycyclic aromatic hydrocarbons (PAHs) in coastal marine sediments: case studies in Cotonou (Benin) and Aquitaine (France) areas. Mar Pollut Bull 2000;40(5):387-396.

Wang Z, Fingas M, Sergy G. Study of 22-year-old arrow oil samples using biomarker compounds by GC/MS. Environ Sci Technol 1994;28:1733-1746.

Wang Z, Fingas M, Landriault M, Sigouin L, Feng Y, Mullin J. Using systematic and comparative analytical data to identify the source of an unknown oil on contaminated birds. J Chromatogr 1997;775:251-265. 